\title{
Changes in healthcare utilization and costs associated with sildenafil therapy for pulmonary arterial hypertension: a retrospective cohort study
}

\author{
Ariel Berger ${ }^{1 *}$, John Edelsberg ${ }^{1}$, Simon Teal ${ }^{2}$, Marko A Mychaskiw ${ }^{3}$ and Gerry Oster ${ }^{1}$
}

\begin{abstract}
Background: Little is known concerning the degree to which initiation of sildenafil for pulmonary arterial hypertension (PAH) impacts patterns of healthcare utilization and costs.

Methods: Using a large US health insurance claims database, we identified all patients with evidence of PAH (ICD9-CM diagnosis codes 416.0, 416.8) who received sildenafil between 1/1/2005 and 9/30/2008. Date of the first-noted prescription for sildenafil was designated the "index date," and claims data were compiled for all study subjects for 6 months prior to their index date ("pretreatment") and 6 months thereafter ("follow-up"); patients with incomplete data during either of these periods were excluded. Healthcare utilization and costs were then compared between pretreatment and follow-up for all study subjects.

Results: A total of 567 PAH patients were identified who began therapy with sildenafil and met all other study entry criteria. Mean (SD) age was 52 (10) years; 73\% were women. Healthcare utilization was largely unchanged between pretreatment and follow-up, the only exceptions being decreases in the mean number of emergency department visits (from 0.7 to 0.5 per patient; $p<0.01$ ) and the percentage of patients hospitalized (from $35 \%$ to $29 \% ; p=0.01$ ). The mean cost of all PAH-related medication was $\$ 7139$ during pretreatment and $\$ 14,095$ during follow-up (sildenafil cost during follow-up $=\$ 5236$ ); exclusive of PAH-related medications, however, total healthcare costs decreased modestly (from $\$ 30,104$ to $\$ 27,605)$ ( $p<0.01$ for all comparisons).
\end{abstract}

Conclusions: The cost of sildenafil therapy may be partially offset by reductions in other healthcare costs.

Keywords: Pulmonary arterial hypertension, Primary pulmonary hypertension, Sildenafil, PDE5, Phosphodiesterase type 5, Health expenditure, Utilization

\section{Background}

Pulmonary arterial hypertension (PAH) is characterized by a pathological narrowing of the pulmonary arterioles and small arteries, which causes elevated pulmonary vascular resistance and increased pressure in the pulmonary arteries and eventually results in the development of right ventricular failure and death $[1,2]$. Dyspnea, fatigue, chest pain, and syncope are the principal presenting symptoms of PAH [3]. The disease is one form of pulmonary hypertension (broadly defined as increased pressure in the pulmonary arteries, capillaries, or veins). In recent classification schemes for pulmonary

\footnotetext{
* Correspondence: aberger@pai2.com

'Policy Analysis Inc. (PAI), 4 Davis Court, Brookline, MA 02445, USA Full list of author information is available at the end of the article
}

hypertension (Dana Point classification [4], guidelines of the European Society of Cardiology and European Respiratory Society [1]), PAH constitutes Group 1 and includes both idiopathic PAH and PAH associated with other specific diseases (Group 2 includes patients with pulmonary hypertension primarily due to left heart disease, Group 3 comprises those with pulmonary hypertension due to chronic pulmonary disease, Group 4 includes cases of chronic thromboembolic pulmonary hypertension, and Group 5 includes miscellaneous types of pulmonary hypertension that do not fit into the other four categories). In epidemiologic studies, the most common types of PAH (in order of decreasing frequency) are: (1) idiopathic; (2) PAH associated with connective tissue disease; and (3) PAH associated with congenital

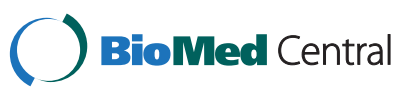


systemic-to-pulmonary shunts in the heart [5-9]. Worldwide, it is estimated that 130,000 to 260,000 persons have PAH [10]. Mean age at diagnosis is $>50$ years, and the disease is more common among women than men. Most patients present with moderate-to-severe disease and prognosis is poor; 5-year survival in the absence of treatment is only about 50\% [9].

The goal of therapy in PAH is to control symptoms of the disease and hopefully slow its progression. Conventional therapy has included the management of underlying or contributing factors, avoidance of pregnancy, early treatment of respiratory tract infections, and immunization against pneumococcal disease and influenza [11]. Calcium channel blockers at high doses also have been an important component of conventional therapy in the small percentage of PAH patients who respond to such therapy.

In recent years, a number of targeted pharmacotherapies have been introduced for the treatment of PAH [12]. There are three main classes of such agents, which act on three main intracellular pathways: (1) prostaglandin/ prostacyclin analogues (e.g., intravenous epoprostenol, nebulized or intravenous iloprost); (2) endothelin receptor antagonists (e.g., oral bosentan); and (3) phosphodiesterasetype 5 (PDE-5) inhibitors (e.g., oral sildenafil). These targeted therapies have been shown to improve exercise capacity, hemodynamics, symptoms, and health-related quality of life [13].

Sildenafil $\left(\right.$ Revatio $\left.^{\circledR}\right)$ is a PDE-5 inhibitor that was approved for the treatment of PAH (to improve exercise capacity) in 2005 in the US and the European Union, and then in 2009, to delay clinical worsening (US only) [14]. While the efficacy and safety of sildenafil are well established, comparatively little is known about the effects of such therapy on healthcare utilization and costs in "real-world" settings. Our study examined this issue using health insurance claims data.

\section{Methods}

\section{Data source}

Data were obtained from the Medstat MarketScan Commercial Claims and Encounters Database. The database is comprised of facility, professional-service, and retail (i.e., outpatient) pharmacy claims from a variety of private insurers, providing healthcare coverage to approximately 15 million persons annually throughout the US. All patient identifiers in the database have been fully encrypted, and the database is fully compliant with the Health Insurance Portability and Accountability Act of 1996. As no patient or provider contact was made, and patient information was de-identified; institutional review board (IRB) approval was not required.

Information available for each facility and professionalservice claim includes date and place of service, diagnoses (in International Classification of Diseases, $9^{\text {th }}$ revision, Clinical Modification [ICD-9-CM] format), procedures (in ICD-9 ${ }^{-} \mathrm{CM}$ [selected plans only], Current Procedural Terminology $4^{\text {th }}$ Edition, and Healthcare Common Procedure Coding System formats), provider specialty, and charged and paid amounts. Data available for each retail pharmacy claim include the drug dispensed (in National Drug Code format), the dispensing date, and the quantity dispensed and number of days of therapy supplied (selected plans only). All claims include a charged amount; the database also provides paid (i.e., reimbursed, including patient deductible, copayment, and/or coinsurance) amounts.

Selected demographic and eligibility information is also available, including age, gender, geographic region, coverage type, and the dates of insurance coverage. All patient-level data can be arrayed in chronologic order to provide a detailed, longitudinal profile of all medical and pharmacy services used by each plan member. The database for this study encompassed the period, January 1, 2005 through September 30, 2008 ("study period").

\section{Study sample}

The source population for our study consisted of all persons with any inpatient claims, or two or more outpatient claims at least 30 days apart, with a diagnosis of pulmonary hypertension (ICD-9-CM diagnosis codes 416.0 [primary pulmonary hypertension] or 416.8 [secondary pulmonary hypertension]) between January 1 , 2005 and September 30, 2008. We included patients with either of these diagnosis codes (i.e., primary or secondary pulmonary hypertension) to ensure complete capture of all those with PAH, since the ICD-9-CM coding system does not coincide with contemporary classification schemes for pulmonary hypertension. Among these patients, we then identified those with one or more pharmacy claims for Revatio, the commercial name of sildenafil that is indicated for the treatment of $\mathrm{PAH}$ (sildenafil is also sold under the brand name of Viagra ${ }^{\circledR}$ for erectile dysfunction; the dosages of Revatio and Viagra differ, however, as do the number of pills supplied per respective prescription). The date of each patient's first-noted claim for Revatio was designated his or her "index date", and claims data were compiled for all study subjects for 6 months prior to their index date ("pretreatment") and 6 months thereafter ("follow-up"). (Revatio is indicated only for the treatment of PAH [14], we therefore assumed that it was initiated only for this disease among patients in our study sample, and consequently did not require that the diagnostic evidence of $\mathrm{PAH}$ occur prior to the index date.) Patients were excluded from the study sample if they: (1) had incomplete data during pretreatment or follow-up; (2) received Viagra during pretreatment; (3) were aged $<18$ years as 
of their index date; or (4) were aged $\geq 65$ years as of their index date if they were not enrolled in a Medicare risksharing (i.e., capitated) plan. While we excluded patients who received Viagra in the pretreatment period, receipt of Viagra during follow-up was not an exclusion criterion (i.e., study subjects were required to have initiated therapy with Revatio, but could have switched to Viagra for reasons related to dosage or cost).

\section{Measures and analyses}

We examined selected demographic and clinical characteristics of study subjects, including the number with various comorbidities (Table 1), based on information during the 6-month pretreatment period. Patients were assumed to have a given condition if they had evidence during pretreatment of either one or more hospitalizations, or two or more outpatient claims at least 30 days apart, with a corresponding diagnosis code and/or prescription. The Charlson comorbidity index also was calculated [15].

Levels of healthcare utilization and cost were examined during pretreatment and follow-up, including services and medications related to the treatment of PAH. PAH-related services were identified based on claims for medical treatment with an ICD-9-CM diagnosis code for PAH. PAH-related medications were assumed to consist of PDE-5 inhibitors (including both Revatio and Viagra), prostaglandin/prostacyclin analogues, endothelin receptor antagonists, nitric oxide/nitric oxide donors, calcium channel blockers, oral anticoagulants/antiplatelets, diuretics, oxygen, and cardiac glycosides. (While many of these medications are prescribed for conditions other than PAH [e.g., calcium channel blockers for hypertension and coronary artery disease], we designated them as "PAH-related" given their potential for use in the treatment of PAH).

The statistical significance of differences in continuous measures was assessed using paired $\mathrm{t}$-tests and Wilcoxon signed-rank tests for measures that were normally and non-normally distributed, respectively; for categorical data, McNemar's and Bowker's tests were used, as appropriate. All analyses were conducted using PC-SAS ${ }^{\circledR}$ v.8.4.

\section{Results}

We identified a total of 567 patients with evidence of $\mathrm{PAH}$ who began therapy with sildenafil and satisfied all other entry criteria (Table 2). Eighty-six percent of patients in the study sample had encounters with ICD9-CM diagnoses of both primary pulmonary hypertension (416.0) and secondary pulmonary hypertension (416.8) during the study period; the remaining $14 \%$ had claims only for primary $(4.3 \%)$ or secondary $(9.7 \%)$ pulmonary hypertension. Mean (standard deviation) age of
Table 1 Comorbidities of interest

\begin{tabular}{ll}
\hline Comorbidity & Definition \\
\hline Connective tissue diseases & ICD-9-CM diagnoses 710.0, 710.1, \\
& $714 . X, 710.3,710.4$ \\
Congenital heart diseases & ICD-9-CM diagnoses 745.3, 745.4, \\
& $745.5,745.6,747.0$ \\
HIV/AIDS & ICD-9-CM diagnoses 042, 079.53, V08 \\
Depressive disorders & ICD-9-CM diagnoses 311, 296.2X, \\
& $296.3 X, 296.5 X, 296.82,300.4,298.0$, \\
Anxiety disorders & $309.0,309.28,309.1$ \\
& ICD-9-CM diagnoses 300.XX, 301.XX, \\
Sleep disorders & 309.21 \\
& ICD-9-CM diagnoses 780.57, 780.50, \\
& $780.51,780.53,307.4 X, 780.5 X, V 69.4$
\end{tabular}

Lung disease

Asthma

ICD-9-CM diagnoses 493.XX

Chronic obstructive pulmonary disease

Pulmonary fibrosis

ICD-9-CM diagnoses 491.XX, 492.XX, 496.XX

Cerebrovascular disease

ICD-9-CM diagnoses 515, 516.3

Coronary heart disease

ICD-9-CM diagnoses 430-438.XX

Atrial fibrillation

ICD-9-CM diagnoses 410-414.XX

ICD-9-CM diagnoses 427.3

Congestive heart failure

ICD-9-CM diagnoses 428.XX

Peripheral vascular disease

ICD-9-CM diagnoses 440.2X, 440.3X 443.9X, 444.22

Hemtaological conditions

ICD-9-CM diagnoses 282.6, 282.49, 289.6, 205.1X

Liver disease

ICD-9-CM diagnoses 572.3, 006.3, 070.22, 070.32, 070.33, 070.44, 070.54, 456.0-456.21, 570-572.29, 572.4- 573.9, 996.82, V42.7

Renal disease

ICD-9-CM diagnoses 293.9, 294.8, 276.0-276.9, 458.21, 567.XX, 584.XX-586.XX, 792.5, 996.1, 996.62, 996.56, 996.68, 996.73, 999.2, 999.3 999.9, V45.1, V56.0, V56.1, V56.2, V56.3X, V56.8, E87.02, E87.91; ICD-9-CM procedures 39.42, 39.43, 39.93, 39.94, 39.9

Diabetes

ICD-9-CM diagnoses 250.XX; receipt of alpha-glucosidase inhibitors, insulin, metformin, nonsulfonylurea insulin secretagogues, sulfonylurea, or thiazolidinedione

Neoplasms

ICD-9-CM diagnosis 140.XX-209.XX, 230.XX-238.XX

HIV/AIDS: Human immunodeficiency virus/Acquired Immune Deficiency Syndrome.

study subjects was 52.3 (9.8) years; $72.7 \%$ were women (Table 3). The percentage of study subjects with selected comorbidities was as follows: connective tissue disease, 18.3\%; congenital heart disease; $4.1 \%$; chronic obstructive pulmonary disease, 19.0\%; pulmonary fibrosis, $12.2 \%$; and congestive heart failure, 23.6\%.

Use of most PAH-related medications increased between pretreatment and follow-up, including prostaglandin/ 


\section{Table 2 Sample selection}

\begin{tabular}{ll}
\hline Criteria & $\begin{array}{l}\text { Number of } \\
\text { patients }\end{array}$ \\
\hline $\begin{array}{l}\text { Total number of patients with } \geq 1 \text { inpatient claims, } \\
\text { or } \geq 2 \text { outpatient claims at least } 30 \text { days apart, } \\
\text { with diagnosis of PAH during study period* and }\end{array}$ & 22101 \\
$\begin{array}{l}\text { One or more pharmacy claims for Revatio during } \\
\text { study period and }\end{array}$ & 1116 \\
$\geq 6$ months enrollment prior to index date** and & 899 \\
Eligible for medical and pharmacy benefits for & 899 \\
duration of study period and & \\
Were aged $\geq 18$ years as of index date and & 856 \\
Were aged $<65$ years as of index date or & 856 \\
Were aged $\geq 65$ years as of index date and enrolled \\
in Medicare \\
Had total costs $\geq \$ 0$ and \\
Had no receipt of Viagra during pre-index period and \\
Had $\geq 6$ months enrollment following index date**
\end{tabular}

*Spanning January 1, 2005 to end of database.

**Defined as the date of the first-noted claim for Revatio.

prostacyclin analogues $(8.1 \%$ of patients received these agents during pretreatment vs $11.1 \%$ during follow-up $[\mathrm{p}=0.01])$, endothelin receptor antagonists $(27.5 \%$ to $31.9 \%[\mathrm{p}=0.01])$, oral anticoagulants $(34.0 \%$ to $41.3 \%$ [p $<0.01])$, diuretics $(61.4 \%$ to $68.3 \%[\mathrm{p}<0.01])$, and cardiac glycosides $(16.6 \%$ to $19.0 \%$ [ $p=0.03]$ ) (Figure 1$)$. Use of calcium channel blockers declined (from $34.9 \%$ to $30.0 \%)(\mathrm{p}<0.01)$. There were few statistically significant differences in healthcare utilization between pretreatment and follow-up, the only exceptions being declines in the mean number of emergency department (ED) visits per patient (from 0.7 to 0.5 per patient; $\mathrm{p}<0.01$ ) and the percentage of patients hospitalized (from $35.1 \%$ to 28.9\%; $\mathrm{p}=0.01)$ (Table 4).

The mean cost of PAH-related medication increased from $\$ 7139$ during pretreatment to $\$ 14,095$ during follow-up $(\mathrm{p}<0.01)$. The cost of PDE-5 inhibitors was $\$ 5236$ during follow-up, almost all of it attributable to Revatio (5 patients had evidence of receipt of Viagra; 3 patients, tadalafil). Mean total healthcare costs increased from $\$ 37,243$ during pretreatment to $\$ 41,700$ during follow-up; exclusive of the cost of PAH-related pharmacotherapy, mean total healthcare costs declined from $\$ 30,104$ to $\$ 27,605$ (both $\mathrm{p}<0.01$ ) (Table 5). Significant reductions were noted in the mean cost of physician office visits (from $\$ 2088$ to $\$ 1935$ ), other outpatient visits (from \$6226 to \$5490), and emergency department visits (from $\$ 355$ to $\$ 310$ ) (all $\mathrm{p}<0.01$ ). There was a nominal, albeit not statistically significant, decline in the mean cost of hospitalization-from $\$ 13,743$ during pretreatment to $\$ 11,602$ during follow-up ( $\mathrm{p}=0.18)$, most likely reflective of the aforementioned decline in the percentage of patients admitted to hospital.
Table 3 Demographic and clinical characteristics of study subjects $(\mathrm{N}=567 *)$

\begin{tabular}{ll}
\hline Characteristic & Value \\
\hline Mean (SD) age, y & $52.3(9.8)$ \\
Number (\%) women & $412(72.7)$ \\
Comorbidities (n [\%]) & \\
Connective tissue diseases & $104(18.3)$ \\
Congenital heart diseases & $23(4.1)$ \\
HIV/AIDS & $1(0.2)$ \\
Depressive disorders & $29(5.1)$ \\
Anxiety disorders & $8(1.4)$ \\
Sleep disorders & $83(14.6)$ \\
Lung disease & \\
Asthma & $33(5.8)$ \\
Chronic obstructive pulmonary disease & $108(19.0)$ \\
Pulmonary fibrosis & $69(12.2)$ \\
Any of above & $172(30.3)$ \\
Cerebrovascular disease & $10(1.8)$ \\
Coronary heart disease & $68(12.0)$ \\
Atrial fibrillation & $46(8.1)$ \\
Congestive heart failure & $134(23.6)$ \\
Peripheral vascular disease & $9(1.6)$ \\
Hematological conditions & $8(1.4)$ \\
Liver disease & $44(7.8)$ \\
Renal disease & $72(12.7)$ \\
Diabetes & $91(16.0)$ \\
Neoplasms & $38(6.7)$ \\
Mean (SD) Charlson comorbidity index & $1.0(1.1)$ \\
\hline PAH: Pumona ateia hypensions & \\
\hline
\end{tabular}

PAH: Pulmonary arterial hypertension; HMO: Health maintenance organization; PPO: Preferred provider; HIV/AIDS: Human immunodeficiency virus/Acquired Immune Deficiency Syndrome.

\section{Discussion}

Mean total healthcare costs during the six-month period following initiation of sildenafil therapy were higher than they were in the period immediately preceding the start of such therapy, due largely to increases in the cost of PAH-related pharmacotherapy. Exclusive of the cost of pharmacotherapy, mean total healthcare costs declined by about $\$ 2500$, primarily as a result of significant reductions in the cost of physician office visits $(-\$ 153)$, other outpatient visits (-\$736), and emergency department visits $(-\$ 45)$.

Since the database that we used does not contain any information on clinical effectiveness per se (e.g., sixminute walk test, cardiopulmonary hemodynamics), our study provides no direct evidence thereof for sildenafil. We believe, however, that our study nonetheless provides some indirect evidence of its effectiveness, if one assumes that costs of care are a reasonably accurate 


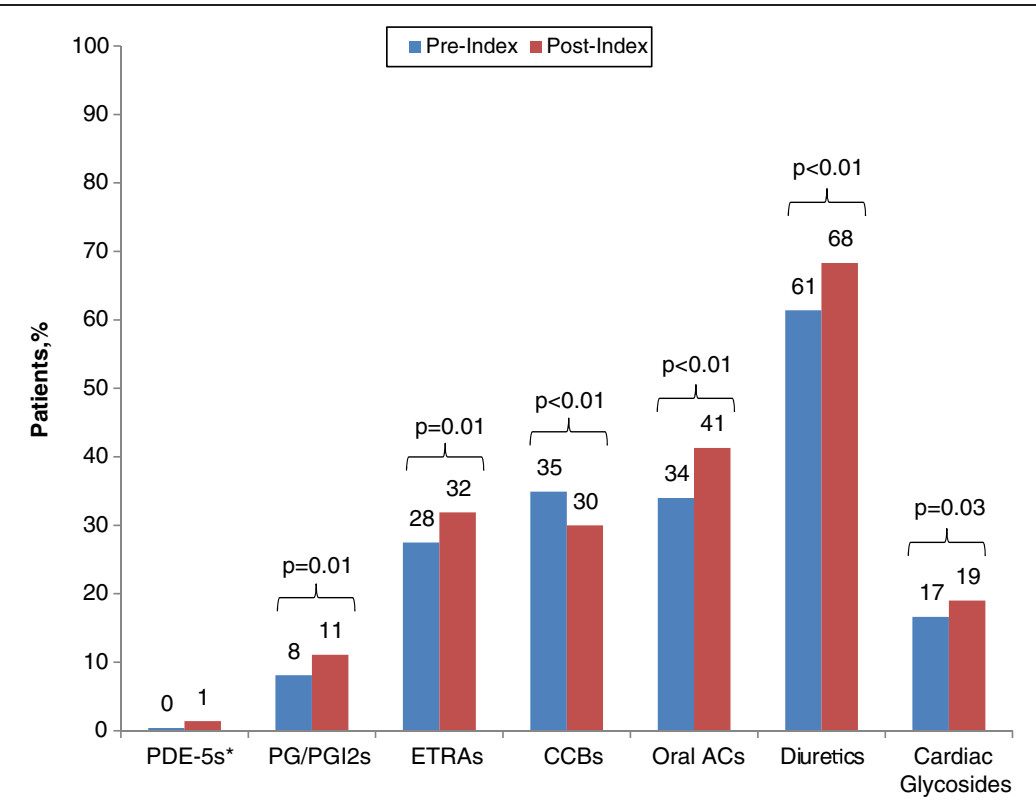

Figure 1 Use of PAH-related pharmacotherapy during pre- and post-index periods. *Excluding sildenafil. PDE-5: Phosphodiesterase type-5 inhibitor; PG/PGI2: Prostaglandin/prostacyclin analogues; ETRA: Endothelin-receptor antagonist; CCB: Calcium-channel blocker; AC: Anticoagulant.

mirror of disease progression and severity. Our finding that the cost of PAH-related inpatient and outpatient care (i.e., exclusive of the cost of PAH-related pharmacotherapy) declined would appear to be consistent with the hypothesis that the efficacy of sildenafil is manifested in clinical practice via reductions in the costs of PAHrelated services $[13,16-24]$. Our finding that initiation of sildenafil therapy appears to be coupled in many patients with increased use of other PAH-related medications is not surprising in a progressive disease such as PAH.

Of course, there are other possible explanations for the reductions in the cost of PAH-related care that we observed. For one, the use of other PAH-related medications, such as prostaglandin/prostacyclin analogues (e.g., iloprost) and endothelin-receptor antagonists (e.g., bosentan), also increased significantly during follow-up. The decline in healthcare costs that we observed may simply be a result of better tailoring of medication regimens to patients' needs and not to the use of sildenafil alone. Cost reductions also could reflect regression to the mean, if there is lability in signs and symptoms and clinicians are more likely to modify medication regimens when patients are doing poorer clinically (e.g., experiencing exacerbation). Given the scant clinical data available to us, the precise reason(s) for observed reductions in healthcare costs following initiation of sildenafil therapy must remain conjectural.

Certain limitations of our study warrant mention. We could not definitively identify patients with $\mathrm{PAH}$ because ICD-9-CM coding for pulmonary hypertension predates current classification schemes. We included patients who received either of the two principal diagnosis codes for pulmonary hypertension $(416.0,416.8)$ to ensure complete capture of all patients with PAH. Although $90 \%$ of study subjects had at least one claim for primary pulmonary hypertension (presumably, idiopathic or heritable PAH), most (86\%) also had claims for other forms of pulmonary hypertension, which could include PAH associated with other disorders (e.g., PAH due to connective tissue disease), as well as other, non-PAH, pulmonary hypertension. The relatively high prevalence of both congestive heart failure (CHF) (a common underlying disease in Group 2 pulmonary hypertension) and chronic obstructive pulmonary disease (COPD) (a common underlying disease in Group 3 pulmonary hypertension) in our study population (24\% and $19 \%$, respectively) further suggests that some degree of misclassification may have occurred. Although it is possible to have both PAH and COPD and/or CHF (right-heart failure develops late in the course of $\mathrm{PAH}$ ), the prevalence of both PAH and CHF or COPD is probably small, which raises the possibility that a proportion of these patients in our sample had Group 2 and Group 3 pulmonary hypertension, respectively. We note, however, that even if there were no overlap between patients with $\mathrm{CHF}$ and those with COPD, and all patients with CHF or COPD had secondary pulmonary hypertension, this would account for only about one-half of all patients with ICD-9-CM diagnosis codes for both primary and secondary pulmonary hypertension. 
Table 4 Use of healthcare services during pre- and post-index periods

\begin{tabular}{|c|c|c|c|}
\hline Service & Pre-index & Post-index & $P$-value \\
\hline \multicolumn{4}{|l|}{ Outpatient services } \\
\hline \multicolumn{4}{|l|}{ Physician office visits } \\
\hline Number (\%) with $\geq 1$ visits & $561(98.9)$ & $559(98.6)$ & 0.48 \\
\hline \multicolumn{4}{|l|}{ Number of visits } \\
\hline Mean $(95 \% \mathrm{Cl})$ & $11.7(11.1,12.4)$ & $12.1(11.3,12.9)$ & 0.60 \\
\hline Median (IQR) & $10(6,15)$ & $10(6,16)$ & \\
\hline \multicolumn{4}{|l|}{ Other outpatient office visits } \\
\hline Number (\%) with $\geq 1$ visits & $550(97.0)$ & $540(95.2)$ & 0.08 \\
\hline \multicolumn{4}{|l|}{ Number of visits } \\
\hline Mean $(95 \% \mathrm{Cl})$ & $10.1(9.4,10.9)$ & $10.3(9.5,11.1)$ & 0.52 \\
\hline Median (IQR) & $8(5,13)$ & $8(4,14)$ & \\
\hline \multicolumn{4}{|l|}{ ED visits } \\
\hline Number (\%) with $\geq 1$ visits & $194(34.2)$ & $140(24.7)$ & $<0.01$ \\
\hline \multicolumn{4}{|l|}{ Number of visits } \\
\hline Mean $(95 \% \mathrm{Cl})$ & $0.7(0.6,0.8)$ & $0.5(0.4,0.7)$ & $<0.01$ \\
\hline Median (IQR) & $0(0,1)$ & $0(0,0)$ & \\
\hline \multicolumn{4}{|l|}{ Hospitalizations } \\
\hline Number (\%) with $\geq 1$ hospitalizations & $199(35.1)$ & $164(28.9)$ & 0.01 \\
\hline \multicolumn{4}{|l|}{ Number of hospitalizations } \\
\hline Mean $(95 \% \mathrm{Cl})$ & $0.5(0.4,0.6)$ & $0.5(0.4,0.5)$ & 0.18 \\
\hline Median (IQR) & $0(0,1)$ & $0(0,1)$ & \\
\hline \multicolumn{4}{|l|}{ Length of stay } \\
\hline \multicolumn{4}{|l|}{ All patients } \\
\hline Mean $(95 \% \mathrm{Cl})$ & $4.3(3.5,5.1)$ & $3.9(3.0,4.7)$ & 0.06 \\
\hline Median (IQR) & $0(0,5)$ & $0(0,3)$ & \\
\hline \multicolumn{4}{|l|}{ Patients with $\geq 1$ hospitalizations } \\
\hline Mean $(95 \% \mathrm{Cl})$ & $8.8(7.3,10.3)$ & $7.8(6.2,9.5)$ & 0.06 \\
\hline Median (IQR) & $5(0,11)$ & $3(0,9)$ & \\
\hline
\end{tabular}

Furthermore, we believe that most study subjects with ICD-9-CM diagnosis codes for primary and secondary pulmonary hypertension had PAH. All study subjects had to have evidence of receipt of sildenafil, which has been approved for the treatment of PAH but not other classes of pulmonary hypertension. We acknowledge that in clinical practice, physicians may prescribe drugs approved exclusively for PAH for patients with other forms of pulmonary hypertension, but note that the inclusion of such patients in our study sample should have imparted a conservative bias to our findings because the costs of sildenafil therapy would have been incurred without the benefits in terms of decreased utilization and cost of healthcare services. The degree to which misclassification actually occurred in our study must remain conjectural.

Finally, we note that we did not include a concurrent control group as part of our study, and that there are well-established threats to validity associated with these types of research designs. While we were mindful of the problems posed by the use of a study design that did not utilize a concurrent control, we were similarly concerned about the comparability of any population of control subjects that we might have designated. Specifically, it would have required that we identify a group of patients beginning therapy with something other than a PDE-5 inhibitor, and then compare changes in healthcare costs (i.e., pre-treatment versus post-initiation) between these patients and those beginning therapy with Revatio. Underlying differences in disease severity and other potentially important clinical parameters, however, could introduce confounding and bias into such a comparison if not adequately controlled for in the analyses. In the end, we elected not to include concurrent controls in our study due these problems. This significant limitation of our study design should be borne in mind, however, 
Table 5 Mean total healthcare costs during pre- and post-index periods*

\begin{tabular}{|c|c|c|c|}
\hline & \multicolumn{3}{|c|}{22,101} \\
\hline & Pre-index & Post-index & $P$-value \\
\hline \multicolumn{4}{|l|}{ Pharmacotherapy } \\
\hline \multicolumn{4}{|l|}{ PAH-related } \\
\hline \multicolumn{4}{|l|}{ Phosphodiesterase type-5 } \\
\hline inhibitors & $2(0,4)$ & $5,236(4963,5510)$ & $<0.01$ \\
\hline \multicolumn{4}{|l|}{ Prostaglandin/prostacyclin } \\
\hline analogues & $1,569(934,2204)$ & 2,271 $(1574,2969)$ & $<0.01$ \\
\hline Endothelin receptor antagonists & $4,686(4009,5363)$ & $5,613(4867,6359)$ & $<0.01$ \\
\hline Calcium channel blockers & $79(66,92)$ & $71(59,83)$ & 0.14 \\
\hline Oral anticoagulants & $31(26,36)$ & $41(35,47)$ & $<0.01$ \\
\hline Diuretics & $61(52,71)$ & $75(64,87)$ & $<0.01$ \\
\hline Oxygen & $708(601,816)$ & $784(684,883)$ & $<0.01$ \\
\hline Cardiac glycosides & $4(3,5)$ & $5(4,6)$ & $<0.01$ \\
\hline Any of above & $7,139(6122,8156)$ & $14,095(12982,15209)$ & $<0.01$ \\
\hline All other & $2,714(2041,3386)$ & $2,876(2323,3428)$ & 0.10 \\
\hline Total pharmacotherapy & $9,853(8614,11091)$ & $16,971(15758,18184)$ & $<0.01$ \\
\hline \multicolumn{4}{|l|}{ Outpatient services } \\
\hline Physician office visits & $2,088(1807,2368)$ & $1,935(1603,2267)$ & $<0.01$ \\
\hline Other outpatient office visits & $6,226(5060,7391)$ & $5,490(4245,6736)$ & $<0.01$ \\
\hline ED visits & $355(270,440)$ & $310(209,411)$ & $<0.01$ \\
\hline Total outpatient services & 8,668 $(7439,9898)$ & $7,735(6401,9070)$ & $<0.01$ \\
\hline Hospitalizations & $13,743(9745,17741)$ & $11,602(8443,14762)$ & 0.18 \\
\hline All other & $4,979(3627,6332)$ & $5,391(3920,6863)$ & 0.96 \\
\hline \multicolumn{4}{|l|}{ Total } \\
\hline \multicolumn{4}{|l|}{ Exclusive of PAH-related } \\
\hline medications & $30,104(25422,34787)$ & $27,605(23536,31674)$ & $<0.01$ \\
\hline \multicolumn{4}{|l|}{ Inclusive of PAH-related } \\
\hline medications & $37,243(32467,42020)$ & $41,700(37470,45931)$ & $<0.01$ \\
\hline
\end{tabular}

*All values are mean $(95 \% \mathrm{Cl})$ total healthcare costs, \$.

and further study would be needed to ascertain more rigorously the true effects of Revatio therapy for PAH.

\section{Conclusions}

In conclusion, while total healthcare costs increased among PAH patients initiating therapy with sildenafil, the cost of such therapy may be partially offset by reductions in other healthcare costs-specifically, those for outpatient and inpatient services.

\section{Competing interests}

All authors reviewed and contributed to the study research plan, interpretation of the data, and the study manuscript. Data management, processing, and analyses were conducted by $A B, J E$, and $G O$. All authors read and approved the final manuscript. $A B$ and $\mathrm{GO}$ take responsibility for the integrity of the work as a whole, from inception to published article. The study was sponsored by Pfizer Inc. AB, JE, and GO are employees of Policy Analysis Inc. who were paid consultants to Pfizer Inc. in connection with the development of this manuscript. ST and MM are employees of Pfizer, Inc

\section{Authors' contributions}

All authors (AB, JE, ST, MM and GO) made substantial contributions to study conception and design, interpretation of data, were involved in manuscript preparation and review, and have given final approval of the version to be published. AB, JE, and $G O$ undertook data analyses.

\section{Financial support}

The study was sponsored by Pfizer Inc. AB, JE, and GO are employees of Policy Analysis Inc. who were paid consultants to Pfizer Inc. in connection with the development of this manuscript. ST and MM are employees of Pfizer, Inc.

\section{Acknowledgements}

Simon Teal and Marko Mychaskiw are full-time employees of Pfizer Inc. The analyses were conducted by Ariel Berger, John Edelsberg, and Gerry Oster, employees of Policy Analysis Inc (PAI). Sophia Zilber, also an employee of PAl, assisted with the statistical programming required for the conduct of this study. All PAl employees were paid consultants for their involvement on this study. Funding for this research, including the development of this 
manuscript, was provided by Pfizer. Pfizer reviewed the study research plan and the study manuscript; data management, processing, and analyses were conducted by PAI.

\section{Author details}

${ }^{1}$ Policy Analysis Inc. (PAI), 4 Davis Court, Brookline, MA 02445, USA. ${ }^{2}$ Pfizer Ltd., Walton Oaks, Dorking Road, Walton-on-the-Hill, Tadworth, Surrey KT20 7NS, UK. ${ }^{3}$ Pfizer Inc., New York, NY 10017, USA.

Received: 15 June 2012 Accepted: 5 December 2012

Published: 11 December 2012

\section{References}

1. Galie N, Hoeper MM, Humbert M, Torbicki A, Vachiery JL, Barbera JA, et al: Guidelines for the diagnosis and treatment of pulmonary hypertension: The Task Force for the Diagnosis and Treatment of Pulmonary Hypertension of the European Society of Cardiology (ESC) and the European Respiratory Society (ERS), endorsed by the International Society of Heart and Lung Transplantation. Eur Heart J 2009, 30:2493-2537.

2. Channick R, Williamson TL: Diagnosis and treatment of pulmonary arterial hypertension. Cardiol Clin 2004, 22:441-452.

3. Rich S, Dnatzker DR, Ayres SM, Bergofsky EH, Brundage BH, Detre KM, et al: Primary pulmonary hypertension. A national prospective study. Ann Intern Med 1987, 107:216-223.

4. Simonneau G, Robbins IM, Beghetti M, Channick RN, Delcroix M, Denton CP, Elliott CG, Gaine SP, Gladwin MT, Jing ZC, Krowka MJ, Langleben D, Nakanishi N, Souza R: Updated Clinical Classification of Pulmonary Hypertension. J Am Coll Cardiol 2009, 54:S32-S42.

5. Peacock AJ, Murphy NF, McMurray JJV, Caballero L, Steward S: An epidemiologic study of pulmonary arterial hypertension. Eur Respir $J$ 2007, 30:104-109.

6. Thenappan T, Shah SJ, Rich S, Gomberg-Maitland M: A USA-based registry for pulmonary arterial hypertension: 1982-2006. Eur Respir J 2007, 30:1103-1110

7. Humbert M, Sitbon O, Chaouat A, Bertocchi M, Habib G, Gressin V, et al: Pulmonary arterial hypertension in France: Results from a national registry. Am J Respir Crit Care Med 2006, 173:1023-1030.

8. Badesch DB, Champion HC, Sanchez MAG, Hoeper MM, Loyd JE, Manes A, et al: Diagnosis and assessment of pulmonary arterial hypertension. J Am Coll Cardiol 2009, 54:S55-S66.

9. D'Alonzo GE, Barst RJ, Ayres SM, Bergofsky EH, Brundage BH, Detre KM, et al: Survival in patients with primary pulmonary hypertension: Results from a national prospective registry. Ann Intern Med 1991, 115:343-349.

10. National Library of Medicine Medical Encyclopedia [http://www.nlm.gov/ medlineplus/ency/article/000112.htm

11. Barst RJ, Gibbs JS, Ghofrani HA, Hoeper MM, McLaughlin W, Rubin L, et al: Updated evidence-based treatment algorithm in pulmonary arterial hypertension. J Am Coll Cardiol 2009, 54:S78-S84.

12. Hamilton N: Therapy Review: An independent review of the currently available data for treatment of hypertension in the UK. South Yorkshire: Pulmonary Hypertension Association UK; 2006.

13. Galie N, Manes A, Negro L, Palazzini M, Bacchi-Reggiani ML, Branzi A: A meta-analysis of randomized controlled trials in pulmonary arterial hypertension. Eur Heart J 2009, 30:394-403.

14. Revatio ${ }^{\circledR}$ prescribing information [http://media.pfizer.com/files/products/ uspi_revatio.pdf]

15. Deyo RA, Cherkin DC, Ciol MA: Adapting a clinical comorbidity index for use with ICD-9-CM administrative databases. J Clin Epidemiol 1992, 45:613-619.

16. Ghofrani HA, Wiederman R, Rose F, Olschewski H, Schermuly RT, Weissmann $N$, et al: Combination therapy with oral sildenafil and inhaled iloprost for severe pulmonary hypertension. Ann Intern Med 2002, 136:515-522.

17. Sastry BKS, Narasimhan C, Reddy NK, Raju BS: Clinical efficacy of sildenafil in primary pulmonary hypertension: A randomized, placebo-controlled, double-blind, crossover study. J Am Coll Cardio 2004, 43:1149-1153.

18. Simonneau G, Rubin LJ, Galie N, Barst RJ, Fleming TR, Frost AE, et al: Addition of sildenafil to long-term intravenous epoprostenol therapy in patients with pulmonary arterial hypertension: A randomized clinical trial. Ann Intern Med 2008, 149:521-530.
19. Badesch DB, Hill NS, Burgess G, Rubin LJ, Barst RJ, Galie N, et al: Sildenafil for pulmonary arterial hypertension associated with connective tissue disease. J Rheumatol 2007, 34:2417-2422.

20. Wilkins MR, Paul GA, Strange JW, Tunariu N, Gin-Sing W, Banya WA, et al: Sildenafil versus endothelin receptor antagonist for pulmonary hypertension (SERAPH) study. Am J Respir Crit Care Med 2005, 171:1292-1297.

21. Galie N, Ghofrani HA, Torbicki A, Barst RJ, Rubin $L$, Badesch D, et al: Sildenafil citrate therapy for pulmonary arterial hypertension. $N$ Eng $J$ Med 2005, 353:2148-2157.

22. Lewis GD, Shah R, Shahzad K, Camuso JM, Pappagianopoulos PP, Hung J, et al: Sildenafil improves exercise capacity and quality of life in patients with systolic heart failure and secondary pulmonary hypertension. Circulation 2007, 116:1555-1562.

23. Pepke-Zaba J, Gilbert C, Collings L, Brown MCJ: Sildenafil improves health-related quality of life in patients with pulmonary arterial hypertension. Chest 2008, 133:183-189.

24. Singh TP, Rohit M, Grover A, Malhotra S, Vijayvergiya R: A randomized, placebo-controlled, double-blind, crossover study to evaluate the efficacy of oral sildenafil therapy in severe pulmonary artery hypertension. Am Heart J 2006, 151:851. e1-5.

\section{doi:10.1186/1471-2466-12-75}

Cite this article as: Berger et al:: Changes in healthcare utilization and costs associated with sildenafil therapy for pulmonary arterial hypertension: a retrospective cohort study. BMC Pulmonary Medicine 2012 $12: 75$.

\section{Submit your next manuscript to BioMed Central and take full advantage of:}

- Convenient online submission

- Thorough peer review

- No space constraints or color figure charges

- Immediate publication on acceptance

- Inclusion in PubMed, CAS, Scopus and Google Scholar

- Research which is freely available for redistribution 